\title{
Survival Analysis of Hemodialysis Patients
}

\author{
Efri Tri Ardianto", Hari Basuki Notobroto², Windhu Purnomo ${ }^{3}$ \\ ${ }^{1}$ Magister Of Public Health, Program Study of Biostatistic and Demographic, Public Health Faculty, \\ Airlangga University, Surabaya, Indonesia \\ ${ }^{2,3}$ Department of Biostatistic and Demographic, Public Health Faculty, Airlangga University, Surabaya, Indonesia
}

\section{Article Info}

Article history:

Received Jun 08, 2016

Revised Aug 11, 2016

Accepted Aug 20, 2016

\section{Keyword:}

Hemodialysis patients

Kaplan-meier

Survival analysis

\begin{abstract}
Survival analysis as a collection of statistical procedures for analyzing the data that its outcome variable was the time to occurrence of an event. Kaplan-Meier method is a type of survival analysis technique, this method is often called the Product Limit Method. Chronic Kidney Disease (CKD) became one of the public health problem throughout the world, including Indonesia. The number of hemodialysis patients has increased every year and have an impact on increasing the number of death in General Hospital Ibnu Sina Gresik. This study was determine the survival of hemodialysis patients using Kaplan-Meier analysis techniques. Non-reactive research with a retrospective cohort using the calculations right censoring. 155 population were taken randomly and sample size of 111 . Data were collected using a checklist. The estimated survival time of female, adult age, further education, patients work, patients without insurance, patients with normal nutritional status, patients with a history of disease, patient with hypertension and patient with diabetic had a better survival time. The insurance status, nutritional status, hypertension, and diabetes mellitus were significant difference to the survival time ( $\mathrm{p}$-value $<0.05$ ). It was necessary special treatment for CKD patients through giving information, education to families and patients to maintain healthy lifestyle.
\end{abstract}

Copyright $@ 2016$ Institute of Advanced Engineering and Science. All rights reserved.

\section{Corresponding Author:}

Efri Tri Ardianto,

Magister Of Public Health, Program Study of Biostatistic and Demographic,

Public Health Faculty, Airlangga University,

Mulyorejo, Surabaya, Indonesia.

Email: efritriardianto@gmail.com

\section{INTRODUCTION}

Survival analysis is often used as a technique for the analysis of cases disease. Survival analysis is a collection of statistical procedures for analyzing the data that its outcome variable was the time to occurrence of an event. By the time that can mean death, incidence of disease, relapse, recovery, return to work or other events in the interests of researchers that can happen to an individual [1].

Identification of risk factors for a disease would be easier using survival analysis techniques. Kaplan-Meier method is a type of survival analysis technique that is frequently used, this method is often called the Product Limit Method [2]. Kaplan-Meier was used to estimate the computational chances of survival as well as describe it in the shape of the survival curve [1]. Kaplan-Meier survival curve is a curve that describes the relationship between the estimated survival function at time with a time of survival.

Chronic Kidney Disease (CKD) is a public health problem worldwide [3]. The Third National Health and Examination Survey (NHANES III) indicate the prevalence of CKD in the United States increased from 10\% in 1988-1994 years to 13.1\% in1999-2004 year. Research in Europe, Australia, and Asia also confirms the increasing prevalence of chronic kidney disease [4]. There are 19.621 patients with kidney failure who receive hemodialysis therapy, there is an increasing number of renal units service training each 
year [5] and people with more than the poor in the amount of 5.119 [6]. East Java is the order of 2 in Indonesia [7]. While the number of patients with kidney failure undergo dialysis listed in the General Hospital Ibnu Sina Gresik increasing every year, in 2012 year reached 481 patients [8]. The increasing number of patients with chronic renal failure is one of the issues that must be resolved and the country in terms of financing also will increase the burden on the state. Renal failure patients undergoing hemodialysis have a very high mortality rate and can only be overcome by replacing the new kidney or renal transplantation is often called.

Riskesdas data in 2013 year showed the number of people with kidney failure increases with the age of the patient even be the main cause of death. In the age group 35-44 years old increased by $(0.3 \%)$, followed by $45-54$ years old of age $(0.4 \%)$, and the age of $55-74$ years old $(0.5 \%)$, the highest in the age group $\geq 75$ years old $(0.6 \%)$. The prevalence in males $(0.3 \%)$ higher than women $(0.2 \%)$, higher prevalence in rural communities $(0.3 \%)$, are not in school $(0.4 \%)$, the work of self-employed, farmers/fishermen/workers $(0.3 \%)[7]$.

Results [9] showed that the characteristics greatly affect quality of life of patients with kidney failure, such as age, sex. According [10] factors that affect the quality life of patients with chronic renal failure is a socio demographic ie gender, age, race/ethnicity, education, occupation and marital status and factors medical ie old undergoing hemodialysis, stage of disease, and medical management undertaken. From the research that age, gender, history of diabetes mellitus, and history of supplement drink consumption is a risk factor for chronic renal failure [11]. According to [12] that obesity may increase the risk factor for kidney disease. Likewise, the results of research [13] Body Mass Index value is high potential for the occurrence of renal failure.

Based on the above, the purpose of this study was to determine the survival of patients with chronic renal failure in hospitals Ibnu Sina Gresik using Kaplan-Meier analysis techniques (Product Limit Method).

\section{RESEARCH METHOD}

This research was the study of non-reactive research and analytical observation using a retrospective cohort design. This study used data medical record chronic renal failure patients in Ibnu Sina Hospital of Gresik. Observations used the calculation right censoring. The independent variable was also called the predictor variables comprised age, sex, education, married, work status, insurance status, medical history, nutritional status, comorbidities hypertension and diabetes mellitus effect on the response, dependent variable was survival in patients with chronic renal failure.

The population in this study is new in poly hemodialysis patients as many as 155 patients. Using the technique of sampling with simple random sampling method,obtained a sample of 111 people. Instruments in this study using a data collection sheet form and checklist.

\section{RESULTS AND ANALYSIS}

\subsection{Statistic Analysis of Kaplan-Meier}

The relationship identification between the response variable and the predictor variables using the Kaplan-Meier method. Failure survival function expressed as reaching failure event (death) and the rate of failure to achieve the death is expressed as a function of hazard. Estimated survival function and hazard function performed by Kaplan-Meier approach so that the probability of occurrence is known to survive.

Characteristics of patient and statistic value of survival time by Kaplan-Meier can be showed on the Table 1. This table shows the patients with chronic renal failure most of the male sex, adult age group (18-63 years old), have the basic education level (Primary School up to Senior High School), worked, and most have married status. According to the characteristics of insurance status more status insurance participants. Based on the characteristics of the nutritional status of patients with chronic renal failure in the dominance of the nutritional status is not normal and most have a prior history of certain diseases. Most comorbidities the patient is hypertensive (non diabetic).

\subsection{Descriptive Analysis of Kaplan-Meier \\ 3.2.1. Gender}

Probability that the group of patients with chronic renal failure with the female gender has a probability of living higher than the group of patients gender to male. that the survival time of patients estimated 212 women had a week that concluded that the male patient has a probability to experience higher mortality than female. 
Table 1. Characteristics and Statistic Value of Survival Time Kaplan-Meier

\begin{tabular}{|c|c|c|c|c|c|c|c|}
\hline & \multirow{2}{*}{ Characteristics } & \multicolumn{3}{|c|}{ Status } & \multicolumn{2}{|c|}{$\begin{array}{l}\text { Median of Survival } \\
95 \% \text { Confidence Interval }\end{array}$} & \multirow{2}{*}{$\begin{array}{c}\mathrm{P} \text {-value } \\
\text { Log-Rank } \\
\text { test }\end{array}$} \\
\hline & & Censor & No Censor & Estimation & $\begin{array}{l}\text { Lower } \\
\text { Bound }\end{array}$ & Upper Bound & \\
\hline & 2. Woman & 30 & 20 & 212.00 & 99.31 & 324.68 & \\
\hline \multirow[t]{2}{*}{ Age } & 1. Adult(18-63 years $)$ & 55 & 46 & 200.00 & 152.27 & 247.47 & 0.530 \\
\hline & 2. Elderly ( $>63$ years) & 3 & 7 & 109.29 & 178.70 & 178.70 & \\
\hline & $\begin{array}{l}\text { 2. Further Education } \\
\text { (Diploma to Doctoral) }\end{array}$ & 7 & 8 & 200.00 & 154.69 & 245.30 & \\
\hline \multirow[t]{2}{*}{ Job Status } & 1. work & 40 & 38 & 184.00 & 145.15 & 222.84 & 0.739 \\
\hline & 2. Unwork & 18 & 15 & 168.00 & 109.49 & 226.50 & \\
\hline \multirow{2}{*}{ Nutritional Status } & 1. Normal & 35 & 15 & 240.00 & 182.89 & 297.10 & 0.006 \\
\hline & Abnormal & 23 & 38 & 144.00 & 117.94 & 170.05 & \\
\hline \multirow[t]{2}{*}{ History Disease } & Yes & 50 & 42 & 208.00 & 133.42 & 282.58 & 0.426 \\
\hline & No & 8 & 11 & 168.00 & 133.29 & 202.70 & \\
\hline \multirow[t]{2}{*}{ Hypertension } & Yes & 47 & 49 & 168.00 & 128.33 & 207.66 & 0.032 \\
\hline & No & 11 & 4 & - & - & - & \\
\hline \multirow{2}{*}{ Diabetes Mellitus } & Yes & 14 & 24 & 132.00 & 95.21 & 168.78 & 0.009 \\
\hline & No & 44 & 29 & 216.00 & 162.18 & 269.81 & \\
\hline
\end{tabular}

\subsubsection{Age}

The probability that the group of patients with chronic renal failure in adult age (18-63 years) has a probability lingers higher than the group of patients aged elderly and adult age estimated survival time of 200 weeks. So it concluded that elderly patients with age (> 63 years) has a probability to experience higher mortality than the adult age group.

\subsubsection{Education}

The probability that the group of patients with chronic renal failure secondary education level has a probability of living is higher than the group of patients with primary education. survival time with higher education levels have an estimate of 200 weeks and the survival time of patients with primary level has estimated survival time of 180 weeks So it was concluded that patients with Chronic Renal Failure Basic Education has a probability to experience higher mortality than patients with advanced education.

\subsubsection{Work}

The probability that the group of patients with chronic renal failure with work status has a probability to survive higher than the group of patients with status does not work. Survival time with work status has estimated survival time of 184 weeks and the patient's status does not work has estimated survival time of 168 weeks. Thus concluded that probability group of patients with Chronic Renal Failure status does not work has a probability to experience higher mortality than the group of patients with work status.

\subsubsection{Marital Status}

The probability that the group of patients with chronic renal failure marital status has a probability to survive higher than the group of patients with unmarried status showed that patients with kidney failure with marital status have an estimate survival time of 180 weeks and patients with status not married do not have an estimate survival time because most patients are married, so it was concluded that probabilities group of patients with status not married has a probability to experience higher mortality than group of patients with marital status.

\subsubsection{Insurance Status}

The probability that the group of patients with chronic renal failure insurance status did not have life insurance has a probability higher than the group of patients to have insurance status. It showed that kidney failure patients with insurance estimated has survival time 160 weeks, so it was concluded that probability group of patients with insurance status has a probability to experience higher mortality than the group of patients with no insurance status. 


\subsubsection{Nutritional Status}

That the probability of a group of patients with chronic renal failure with normal nutritional status has remained alive probability higher than the group of patients nutritional status is not normal. showed that renal failure patients with normal nutritional status has estimated survival time of 240 weeks, so it was concluded that the group of patients with normal nutritional status has a probability to experience higher mortality than the group of patients with normal nutritional status.

\subsubsection{Disease History}

The probability that the group of patients with chronic renal failure with a medical history has a probability higher alive than those who are not with history of disease. Showed that patients with a history of renal failure have an estimate survival time of 208 weeks. Thus concluded that probability group of patients have no history of the disease has a probability to experience higher mortality.

\subsubsection{Hypertension}

That chronic renal failure patients with comorbidities hypertension do not have a probability of survival than patients with renal failure comorbidities hypertension. Indicates that the probability of patients with hypertension not experience death (still alive) estimated 160. Thus concluded that probability group with comorbidities hypertension has a probability to experience higher mortality.

\subsubsection{Diabetes Mellitus}

That chronic renal failure patients with comorbidities not diabetes mellitus have a higher chance of survival than patients with renal failure comorbidities of diabetes mellitus. It shows that the probability of chronic renal failure patients with diabetes mellitus not to not experience death (still alive) estimated 216 weeks. Thus, concluded that probability group of patients with comorbidities of diabetes mellitus has a probability to experience higher mortality.

Figure 1 is curve of the analysis Kaplan-Meier results based on the predictor variables of hemodialysis patients. This Kaplan-Meier curves showed four variables showed there is a difference in time between two categories, but the curve is merely subjective. To obtain maximum results should be tested with statistical values. Based on Table 1, the test results Log-rank statistics show that the significant variables with p-value $<0.05$ was variable Insurance Status, Nutritional Status, Hypertension and Diabetes Mellitus thus concluded that there are differences in survival time.

\section{DISCUSSION}

\subsection{Insurance Status}

The results showed that the group of patients with chronic renal failure insurance status did not have life insurance has a probability higher than the group of patients to have insurance status. According [14] his High incidence of death in patients with chronic renal failure who have insurance membership can be influenced by behavioral factors. Someone who get health insurance will have a tendency to do activities without concern, as well as with health care, they will tend to pay less attention to health care and will underestimate the condition of illness, because they will take advantage of free medical treatment without the cost, these conditions will be very different with patients who do not have insurance membership, they have a tendency to pay more attention to the disease as if they were sick they had to pay to go to the doctor or hospital. This is consistent with research [9] that one of the characteristics that affect the quality of life of patients with chronic renal failure is the seriousness of someone in maintaining good health in the move, break, or psychologically, stage of disease and medical management were undertaken also influences.

\subsection{Nutritional Status}

The results showed that the group of patients with Chronic Renal Failure with Normal nutritional status has remained alive probability higher than the group of patients nutritional status is not normal. This is in line with research [15] that the relationship affected the quality of life of patients CRF nutrition, the more ugly the more ugly nutritional status of quality of life.[16] showed that overweight (BMI $>25 \mathrm{~kg} / \mathrm{m}^{2}$ ) at age 20 was associated with a significant three-fold excess risk for CRF, relative to $\mathrm{BMI}<25$. 


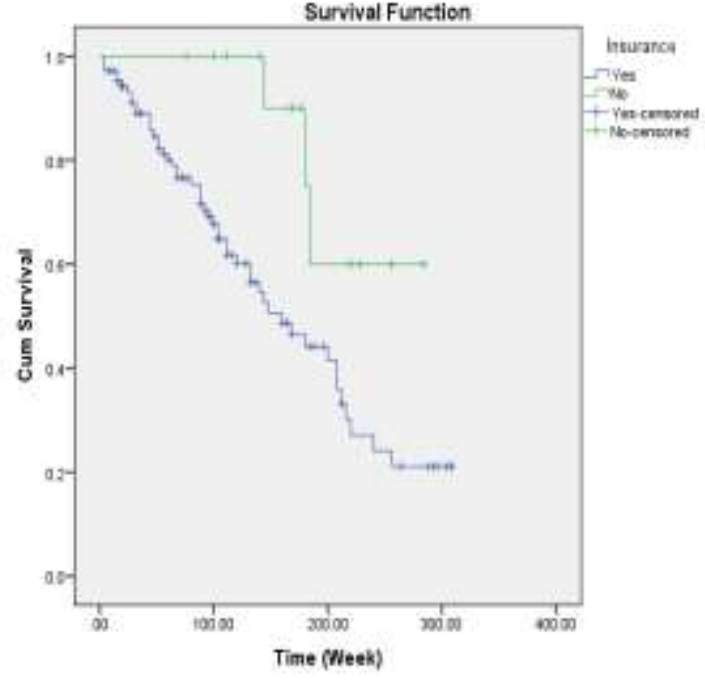

(a)

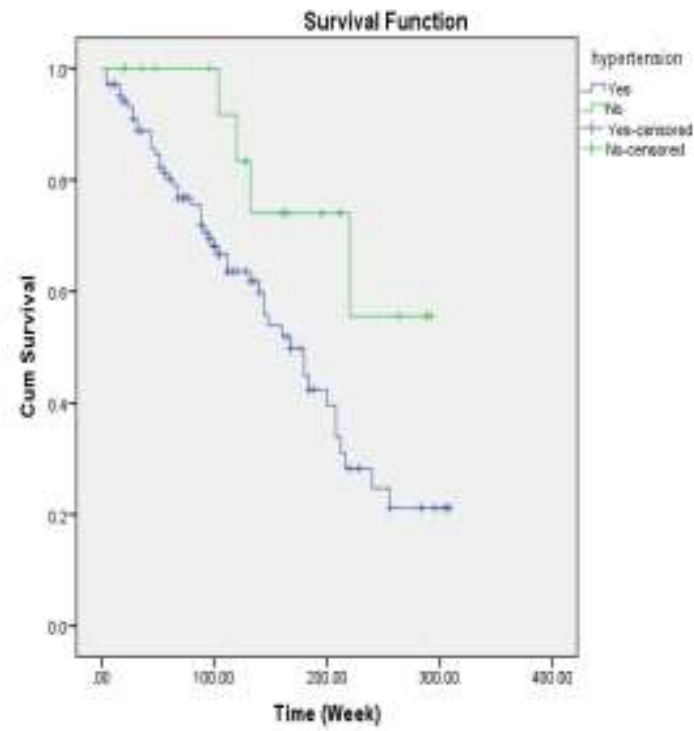

(c)

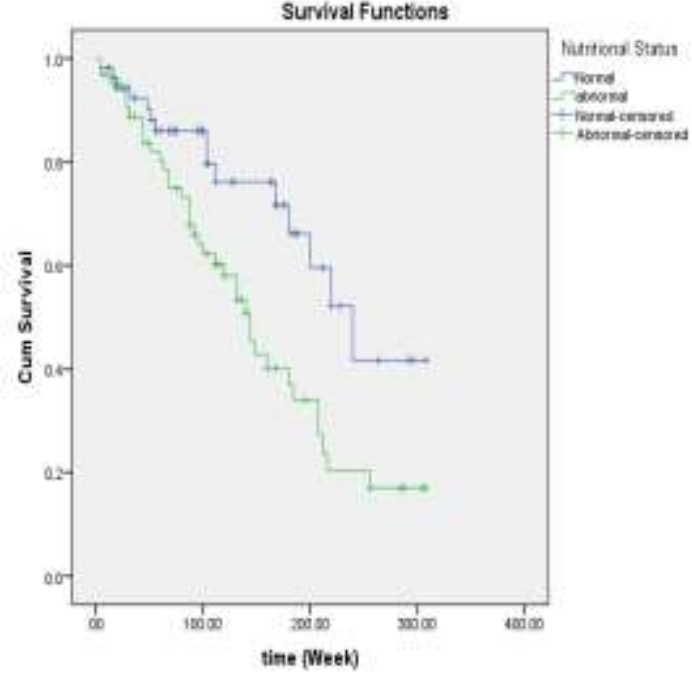

(b)

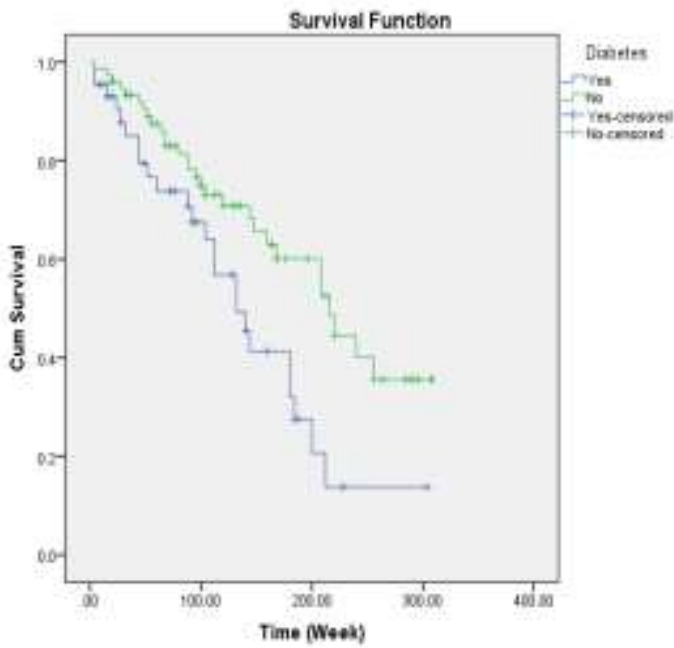

(d)

Figure 1. The Results of Kaplan-Meier Analysis (a) Insurance Status, (b) Nutritional Status,

(c) Hypertension, (d) Diabetes Mellitus

\subsection{Hypertension}

The results showed that chronic renal failure patients with comorbidities hypertension do not have a chance of survival than patients with renal failure comorbidities hypertension. According to the results of research [10], factors that influence the CRF patient is hypertensive, so patients with hypertension 4.6 times life is not qualified than not with hypertension. And according Ingsathit [17] hypertension, diabetes, gout, may influence the occurrence of chronic renal failure. According [10] Chronic renal failure patients with concomitant diseases Hypertension many as $78.9 \%$ of other diseases and According [18] There is a significant correlation between renal disease with history of hypertension, diabetes mellitus, urinary tract infections and urinary tract stones 


\subsection{Diabetes Mellitus}

The results showed that chronic renal failure patients with comorbidities not diabetes mellitus have a higher chance of survival than patients with renal failure comorbidities of diabetes mellitus. According to research [19] patients with CRF were not caused by DM nephropathy total 25 persons (78.1\%). This is according to research [15] states that $30 \%$ of patients with chronic renal failure have comorbidities of diabetes mellitus and $70 \%$ non-morbidities caused by diabetes mellitus.

\section{CONCLUSION}

Based on the results of research and discussion it is concluded that the factors affecting survival in Chronic Renal Failure patients were age, sex, education, marriage, work status, insurance status, history of disease, nutritional status, comorbidities hypertension and comorbidities of diabetes mellitus. So it concluded that patients who have a better survival of the patients were female, aged adults (18-63 years), advanced education (Diploma-Doctoral), marital status, working status, do not have insurance, normal nutritional status, have a history disease, did not have comorbidities hypertension and do not have comorbidities of diabetes mellitus.

\section{SUGGESTION}

The characteristic factors known affect survival of patients so the preventive measures can be carried out and special treatment for chronic renal failure patients who have comorbidities hypertension, diabetes mellitus, so that the patient's life expectancy can be increased. Providing information and education counseling to families and patients with chronic renal failure who have insurance membership to maintain health and a healthy lifestyle. It is necessary to conduct further research to examine other factors that have not been researched in this study.

\section{REFERENCES}

[1] D. G. Kleinbaum, M. Klein, "Survival Analysis a self-learning text," 3nd. ed., USA, Springer Science+Business Media, Inc, 2012.

[2] Yasril and Kasjono, "Multivariate analysis for health research," Yogyakarta, Mitra Cendikia Press, 2009.

[3] A. S. Levey, K. U. Eckardt, Y. Tsukamoto, A. Levin, J. Coresh, J. Rossert, G. Eknoyan, "Definition and classification of chronic kidney disease: a position statement from Kidney Disease: Improving Global Outcomes (KDIGO)," Kidney international, vol/issue: 67(6), pp. 2089-2100, 2005.

[4] F. Hosseinpanah, F. Kasraei, A. A. Nassiri, F. Azizi, "High prevalence of chronic kidney disease in Iran: a large population-based study," BMC public Health, vol/issue: 9(1), pp. 1, 2009.

[5] PERNEFRI, "5th Annual Report of Indonesia Renal Registry,” Indonesia, 2012.

[6] PERNEFRI, “4th Annual Report of Indonesia Renal Registry,” Indonesia, 2011.

[7] The Ministry of Health, "Basic Health Research," Jakarta, Badan Litbangkes, 2013.

[8] The Government of Gresik, "Gresik in Figures," Gresik, 2012.

[9] A. Yuliaw, "Individual Characteristics relationship with Quality of Life Physical Dimensions Chronic Renal Failure patients in the RSUP DR. Kariadi Semarang," 2009. Available From: digilib.unimus.ac.id/files/disk1/106/jtpunimus-gdl-annyyuliaw-5289-2-bab2.pdf on date 28 Pebruari 2016.

[10] Nurcahyati S., "Analysis of factors associated with quality of life patients with chronic kidney disease who undergo hemodialysis at the Islamic Hospital Fatimah Cilacap and Banyumas General Hospital," 2010. On date 28 Mei 2016. Available from: http://repository.usu.ac.id/bitstream/123456789/43193/2/Reference.pdf.

[11] N. Restianika, "Factors Associated With Chronic Renal Failure In Genesis Inpatient Space Medicine at the Hospital Dr. Soeroto Ngawi," Skripsi, Jember University, 2014.

[12] M. C. Foster, S. J. Hwang, M. G. Larson, et al., "Overweight, obesity, and the development of stage 3 CKD: the Framingham Heart Study," American Journal of Kidney Diseases, vol/isue: 52(1), pp. 39-48, 2008.

[13] C. Y. Hsu, C. E. McCulloch, C. Iribarren, J. Darbinian, A. S. Go, "Body mass index and risk for end-stage renal disease," Annals of internal medicine, vol/issue: 144(1), pp. 21-28, 2006.

[14] E. T. Ardianto, "Modeling of Cox proportional hazard classic-Multivariate Adaptive Regression Spline in Hemodialysis Patient Survival in Ibnu Sina Hospital of Gresik," Thesis, Airlangga University, 2016.

[15] A. Yuwono, "Quality of Life According to Spitzer On The Chronic Renal Failure Patients Undergoing Hemodialysis In hemodialysis unit DR. Kariadi Semarang," Doctoral dissertation, Megister Program, Diponegoro University), 2000.

[16] E. Ejerblad, C. M. Fored, P. Lindblad, J. Fryzek, J. K. McLaughlin, O. Nyrén, "Obesity and risk for chronic renal failure," Journal of the American society of nephrology, vol/issue: 17(6), pp. 1695-1702, 2006.

[17] A. Ingsathit, A. Thakkinstian, A. Chaiprasert, P. Sangthawan, P. Gojaseni, K. Kiattisunthorn, B. Mittal, "Prevalence and risk factors of chronic kidney disease in the Thai adult population: Thai SEEK study," Nephrology Dialysis Transplantation, vol/issue: 25(5), pp. 1567-1575, 2010. 
[18] S. Tjekyan, "Prevalence and Risk Factors for Chronic Kidney Disease in Hospital Dr. Mohammad Hoesin Palembang Year 2012," Medicine Magazine of Sriwijaya, vol/issue: 46(4), pp. 275-281, 2014.

[19] Sagala, Deddy Sepadha Putra, "Analysis of Factors Affecting the Quality of Life of Patients with Chronic Renal Failure Undergoing Hemodialysisin General Hospital Haji Adam Malik Medan," Scientific Journal of Nursing, vol/issue: 1(1), 2015 